\title{
LA DIRECTIVA 2011/99/UE DEL PARLAMENTO EUROPEO Y DEL CONSEJO DE 13 DE DICIEMBRE DE 2011) SOBRE LA ORDEN EUROPEA DE PROTECCIÓN: SU APLICACIÓN EN ESPAÑA A LAS VÍCTIMAS DE VIOLENCIA DOMÉSTICA Y DE GÉNERO
}

\author{
The European Parliament's Resolution 2011/99/UE and the Resolution of the \\ Council of December, 13, 2011 regarding the European Order of Protection: \\ its applicability in Spain to the victims of domestic and gender violence
}

Ma Paula Díaz Pita

\begin{abstract}
Sumario
I. Introducción. II. La adopción de la Orden Europea de Protección en el ámbito de la violencia doméstica y de género. 1. Concepto y naturaleza. 2. Supuestos en que procede. 3. Procedimiento de adopción de la Orden Europea de Protección: A) Legitimación. B) Órganos competentes para recibir la solicitud y adoptar una Orden Europea de Protección. C) Tramitación de la solicitud y adopción de la Orden Europea de Protección ante los órganos judiciales españoles. D) El contenido de la Orden Europea de Protección.
\end{abstract}

Resumen: se examina en este artículo los problemas que plantea la entrada en vigor de la Directiva 2011/99/UE del Parlamento Europeo y del Consejo de 13 de Diciembre de 2011 sobre la Orden Europea de Protección que nace con la finalidad de garantizar que la protección ofrecida a una persona física en un Estado miembro de la Unión Europea, se mantenga y continúe en cualquier otro Estado miembro al que la persona vaya a trasladarse o se haya trasladado.

Palabras clave: orden de protección europea, cooperación judicial en materia penal en la UE, víctimas, violencia de género, violencia doméstica.

Abstract: In this work we examinate problems created by the entry into force of Directive 2011/99/UE of de European Parliament and the Council of 13 December 2011 on the European protection order born with the finality to ensure that the protection provided to a natural person in one Member State of the UE is maintained and continued in any other Member State to which the person moves or has moved.

Keywords: the european protection order, judicial cooperation in criminal matters in the EU, victims, gender violence, domestic violence.

\footnotetext{
* Es licenciada y doctora en Derecho procesal penal por la Universidad de Sevilla. Profesora doctora contratada y actual Vicedecana de alumnos de la Facultad de Derecho de laUniversidad de Sevilla, ha publicado varios libros y artículos científicos en España, Argentina, y México.
} 


\section{INTRODUCCIÓN}

La Exposición de Motivos de nuestra Ley Orgánica 1/2004, de 28 de diciembre, de Medidas de Protección Integral contra la Violencia de Género (en adelante LIVG) señala en su Exposición de Motivos que la violencia de género, las agresiones a las mujeres por el solo hecho de su condición femenina, han dejado de ser un "delito fantasma", al que la sociedad volvía la espalda minimizando su gravedad, para pasar a convertirse, en la actualidad, en conductas delictivas "que producen un rechazo colectivo y una evidente alarma social".

Y, asimismo, nos recuerda que ya la Organización de Naciones Unidas en la IV Conferencia Mundial de 1995 reconoció que “(....) la violencia contra las mujeres es un obstáculo para lograr los objetivos de igualdad, desarrollo y paz, y viola y menoscaba el disfrute de los derechos humanos y las libertades fundamentales".

En el ámbito de la Unión Europea, ya "en 1986, el Parlamento estableció un catálogo de 77 medidas destinadas a erradicar la violencia de género que comprendía, entre otras, las intervenciones educativas en la infancia, la reforma de las legislaciones penales de los Estados, la formación de los agentes implicados y medidas de aseguramiento de las víctimas, de elaboración de estadísticas que faciliten la valoración y el diagnóstico del problema, así como de promoción de campañas para la concienciación, destacándose, entre ellas, la de "Tolerancia Cero, ante la violencia contra las mujeres”, desarrollada en 1996 por el mismo Parlamento, que como punto fundamental convirtió en Convenio vinculante para la UE, la Declaración de la Cuarta Conferencia Mundial de Pekín de 1995 e insistió en definir el problema de la violencia contra la mujer, como un problema público que no ha de ser considerado tabú y privado de la mujer que lo sufre (...) instando a los Estados miembros, a adoptar un elenco de hasta 40 medidas para erradicarla entre las que ya se recogieron la necesidad de crear Registros que sistematicen los casos de violencia contra las mujeres y la coordinación con policía, servicios sociales (...) así como la revisión de los procedimientos judiciales, en orden a remover los obstáculos que impidan a las mujeres obtener una adecuada protección jurídica”. ${ }^{1}$

Tras la "declaración de 1999 como "Año Europeo de lucha contra la violencia contra la mujer", con Conclusiones tales como que, una de cada cuatro mujeres en la Unión Europea, sufre violencia física, y más del 10\% es objeto de violencia sexual (...)”2, se adopta la Decisión $n^{\circ}$ 779/2007/CE del Parlamento Europeo y del Consejo por la que se establece un Programa comunitario específico que tiene por objeto prevenir y combatir la violencia ejercida sobre la infancia, los jóvenes y las mujeres y proteger a las víctimas y a los grupos de riesgo, denominado Programa Daphne III, integrado en el Programa General "Derechos fundamentales y Justicia”, cuya aplicación está prevista para el periodo 2007 - 2013. Este Programa no es de nuevo cuño, sino que, por el contrario, tiene sus antecedentes en los Programas Daphne (para el periodo 2000 - 2003) y Daphne II (para el periodo 2004 - 2008), aprobados por sendas Decisiones del Parlamento Europeo y del Consejo, respectivamente, de 24 de enero de 2000 y 21 de abril de 2004.

\footnotetext{
1 Gallego Sánchez, G, "La violencia contra la mujer en la Unión Europea. La Directiva 2011/99/UE: la Orden Europea de Protección”, en Revista de Jurisprudencia, no 4, 29 de Marzo de 2012; BALAGUER CALLEJÓN, M.L. "Crónica de Legislación Europea", pp. 1-4, en ReDCE, Año 8, Na 16, Julio/Diciembre 2011, pp. 521-531.

2 Gallego Sánchez, G, op. cit. 
En lo que se refiere a la lucha en el ámbito de la Unión Europea para erradicar la violencia de género, el mencionado Programa Daphne III tiene como objetivo, por un lado, poner de manifiesto las graves repercusiones que, sobre la salud física y psíquica, tiene la violencia ejercida sobre las mujeres, por el otro, tratar de adoptar las medidas de prevención necesarias para evitar esas situaciones de violencia, y, por último, crear marcos de política comunitaria en esta materia reconociendo que la efectividad de las medidas que puedan adoptarse ha de encomendarse prioritariamente a las autoridades de los Estados miembros de la Unión Europea y a las organizaciones regionales y locales que colaboran con ellos en la ejecución práctica de las mismas.

El Programa Daphne III tendrá, en el futuro, continuidad al quedar integrado en el Programa de Derechos y Ciudadanía, para el periodo 2014-2020,3 cuyo objetivo general será contribuir a la creación de un espacio en el que se promuevan y protejan los derechos de las personas consagrados en el Tratado de Funcionamiento de la Unión Europea y en la Carta de los Derechos Fundamentales de la Unión Europea y, en particular, entre otros, los derechos derivados de los principios de no discriminación y de igualdad entre hombres y mujeres, así como adoptar medidas para combatir la violencia contra las mujeres en todas sus formas ya que constituye una violación de los derechos fundamentales, y al estar presente en todo el territorio de la Unión, es necesaria una actuación coordinada entre todos los Estados Miembros para combatirla.

Las recomendaciones de la Unión Europea en materia de lucha contra la violencia de género no han encontrado, sin embargo, el seguimiento y proyección deseadas en la práctica totalidad de los países de su ámbito de influencia; razón, por la cuál, la Ley Integral española de 2004 es una destacada precursora en esta materia haciéndose eco de un grave problema que afecta no sólo a la sociedad española y a los Estados integrantes de la Unión, sino que constituye una lacra en todos los países de mundo.

Es por ello que el Programa de Estocolmo: Una Europa abierta y segura que sirva y proteja al ciudadano 4 "(...) insta a la Comisión y a los Estados miembros a examinar los modos de mejorar la legislación y las medidas prácticas de apoyo a la protección de las víctimas y prevé, asimismo, la posibilidad de ofrecer a las víctimas del delito medidas especiales de protección que deben ser efectivas en toda la Unión", con la clara finalidad de amparar a las víctimas (y no solo a las de violencia de género), cuando la violencia que sufren traspasa las fronteras de un Estado.

En este sentido, ya la Resolución del Parlamento Europeo, de 26 de noviembre de 2009, sobre la eliminación de la violencia contra la mujer, instaba a los Estados miembros a que mejoraran sus legislaciones y políticas nacionales destinadas a combatir todas las formas de violencia contra la mujer y a que emprendieran acciones de prevención, y garantía del derecho de asistencia y ayuda a todas las víctimas de la violencia, proponiéndose, en concreto, el establecimiento de una Orden Europea de Protección de las víctimas efectiva en todos los países de la Unión, propuesta que fue, posteriormente refrendada, por la Resolución del Parlamento Europeo, de 10 de febrero de 2010, sobre la igualdad entre mujeres y hombres en la Unión Europea.

Esta protección transfronteriza de las víctimas de violencia de género se ha visto, finalmente, implementada con la promulgación, a iniciativa, entre otros países, de España, de

\footnotetext{
3 Propuesta de Reglamento del Parlamento Europeo y del Consejo por el que se establece el Programa de Derechos y Ciudadanía para el periodo 2014 a 2020 /COM/2011/o758 final - 2011/0344 (COD).

4 DO C 115 de 4.5.2010, p. 1
} 
la Directiva 2011/99/UE del Parlamento Europeo y del Consejo de 13 de Diciembre de 2011 sobre la Orden Europea de Protección, ${ }^{5}$ en cuyo Considerando 6 se proclama que "en un espacio común de justicia sin fronteras interiores es menester garantizar que la protección ofrecida a una persona física en un Estado miembro se mantenga y continúe en cualquier otro Estado miembro al que la persona vaya a trasladarse o se haya trasladado. Debe garantizarse asimismo que el ejercicio legítimo por parte de los ciudadanos de la Unión de su derecho a circular y a residir libremente en el territorio de los Estados miembros en virtud del artículo 3, apartado 2, del Tratado de la Unión Europea (TUE) y del artículo 21 del TFUE, no vaya en menoscabo de su protección".

Nace, por consiguiente, la Orden Europea de Protección con la finalidad de que la protección derivada de determinadas medidas de protección dictadas con arreglo al Derecho interno de un Estado miembro pueda ampliarse a otro Estado miembro en el que la persona objeto de la protección decida residir o permanecer.

El propósito de este trabajo no es otro que el de someter a análisis la regulación contenida en la Directiva 2011/99/UE del Parlamento Europeo y del Consejo de 13 de Diciembre de 2011 sobre la Orden Europea de Protección, en lo que se refiere al procedimiento de solicitud y adopción de la misma en concreto en los supuestos de violencia doméstica y de género, examinando cuáles serían, a nuestro juicio, los posibles obstáculos para su plena aplicación en el ámbito del Derecho procesal penal español cuando la Orden Europea de Protección haya de ser emitida por las autoridades españolas competentes.

Para ello, es necesario partir de la base de que la propia Directiva afirma, en no pocas ocasiones, que para la adopción o ejecución de una Orden Europea de Protección (en adelante OEP) no existe obligación de los Estados Miembros de modificar sus sistemas procesales penales nacionales (Considerando 8 y 10), aunque, no obstante, les insta a poner en vigor las disposiciones legales, reglamentarias y administrativas necesarias para dar cumplimiento a lo dispuesto en la Directiva, estableciendo como fecha límite para ello, el 11 de enero de 2015 (art. 21,1 de la Directiva).

La directa aplicación de la Directiva que regula la OEP se asienta, por consiguiente, en el principio de confianza mutuo y en el del mutuo reconocimiento de las sentencias y resoluciones judiciales que proclama el artículo 82, apartado 1, del Tratado de Funcionamiento de la Unión Europea (TFUE) y que, como es conocido, tiene como objetivo mantener y desarrollar un Espacio de Libertad, Seguridad y Justicia.

La entrada en vigor de la Directiva, que se produjo a los veinte días de su publicación, no ha dado lugar, a la promulgación de ninguna normativa específica en el ámbito del ordenamiento procesal penal español, por lo que resulta necesario determinar, de un lado, en qué medida sus disposiciones son compatibles con las vigentes normas sobre medidas de protección de las víctimas de violencia doméstica y de género, $y$, de otro, qué concretas pres-

\footnotetext{
5 Esta Directiva es producto de la Resolución de 10 de junio de 2011 del Consejo sobre un Plan de trabajo para reforzar los derechos y la protección de las víctimas, en particular en los procesos penales, en la que se señala que debía llevarse a cabo una actuación a escala de la Unión para reforzar los derechos y la protección de las víctimas de delitos. Indica, en este contexto, que debía crearse un mecanismo encaminado a asegurar el reconocimiento mutuo entre los Estados miembros de las decisiones en relación con las medidas de protección de las víctimas del delito.
} 
cripciones son aplicables por analogía y cuáles otras sería conveniente incorporar a nuestro derecho interno a los efectos de garantizar y facilitar la solicitud y adopción de una OEP.

\section{LA ADOPCIÓN DE LA ORDEN EUROPEA DE PROTECCIÓN EN EL ÁMBITO DE LA VIOLENCIA DOMÉSTICA Y DE GÉNERO}

\section{CONCEPTO Y FINALIDAD}

Aún cuando el Considerando 9 de la Directiva establece claramente que la OEP puede ser adoptada para proteger y amparar "a cualquier víctima y no solo a las víctimas de la violencia de género", lo cierto es que la expresa referencia a esta clase de víctimas (a la que debemos añadir las víctimas de violencia doméstica) nos lleva a plantearnos la compatibilidad de la adopción de la misma con la regulación contenida tanto en la Ley de Enjuiciamiento Criminal (en adelante LECrim) como en la LIVG, como consecuencia de la aplicación directa de la Directiva en nuestro ordenamiento procesal, a la que aludíamos anteriormente.

Y para ello, es necesario delimitar, en primer lugar, qué entiende la mencionada Directiva por OEP y cuál ha de ser su finalidad; circunstancias éstas (concepto y finalidad) que se encuentran íntimamente relacionadas entre sí, y, a las que hay que sumar, como veremos con posterioridad, la concurrencia de una serie de requisitos para su solicitud y posterior adopción.

Pues bien, la adopción de una OEP supone, según establece el art. 1 de la Directiva, la ampliación a otro Estado Miembro (al que la víctima se haya trasladado o pretenda trasladarse) de la protección derivada de determinadas medidas dictadas por la autoridad competente del Estado de emisión de acuerdo con las normas procesales de su Derecho interno, manteniéndose así la protección de una persona en el territorio de otro Estado Miembro.

No constituye, por consiguiente, la OEP una medida de protección autónoma sino que, por el contrario, se encuentra preordenada a la previa existencia de una medida de protección adoptada por la autoridad competente de un Estado Miembro. De ahí que, por un lado, el art. 2,5 de la Directiva exija como requisito de admisibilidad de la solicitud de una OEP que se haya adoptado previamente una medida de protección en el Estado de emisión, y, por el otro, reitere el art. 5 de la Directiva que "solo se podrá dictar una orden europea de protección cuando previamente se haya adoptado en el Estado de emisión una medida de protección que imponga a la persona causante del peligro una o varias de las prohibiciones o restricciones (..)" que en el mismo se enumeran.

Partiendo de la consideración del Estado español como Estado de emisión de una OEP, y trasladado todo ello al ámbito de nuestro ordenamiento procesal penal , más concretamente, en relación con las medidas de protección y seguridad de las víctimas de violencia de género y doméstica, resultaría, en una primera aproximación, que la solicitud de una OEP ante las autoridades competentes, quedaría condicionada a la previa existencia de cualquiera de las medidas de protección previstas tanto en la LECrim como en la LIVG.

Como tales medidas de protección de las víctimas de violencia de género, en el ámbito de nuestro derecho interno, el Título V de la LIVG contempla la adopción de una serie de medidas que denomina de Tutela Judicial y que comprenden desde la creación de los Juzgados de Violencia sobre la Mujer y del Fiscal contra la Violencia sobre la Mujer, hasta la regulación de las Medidas de protección y de seguridad de las víctimas que, conforme a lo dispuesto en el 
art. 61, 1 “... serán compatibles con cualesquiera de las medidas cautelares y de aseguramiento que se puedan adoptar en los procesos civiles y penales". Más concretamente, el art. 62 de la LIVG prevé, entre las medidas judiciales de protección y seguridad, que las víctimas de la violencia de género pueden solicitar la denominada Orden de Protección, cuyo régimen jurídico se encuentra desarrollado en el art. 544 ter de la LECrim (al que expresamente se remite).

Con respecto a las víctimas de violencia doméstica, podrán, asimismo, solicitar la Orden de Protección conforme a lo dispuesto en el mencionado art. 544 ter de la LECrim, previsión que es anterior en el tiempo dado que este precepto fue introducido en el citado cuerpo legal por la Ley 27/2003, de 31 de julio, reguladora de la Orden de Protección de las víctimas de la violencia doméstica siendo su apartado $1^{\circ}$ modificado posteriormente por la L.O. 15/2003, de 25 de noviembre de modificación del Código Penal.

A tenor de lo dispuesto en el apartado $5^{\circ}$ del art. 544 ter de la LECrim según el cual "la orden de protección confiere a la víctima .... un estatuto integral de protección que comprenderá las medidas cautelares de orden civil y penal ... y aquellas otras medidas de asistencia y protección social establecidas en el ordenamiento jurídico", es evidente que aquélla no constituye, en sí misma, ninguna medida cautelar6, sino que, por el contrario, lo que con ella se pretende es otorgar a la víctima, de actos tanto de violencia doméstica como de violencia de género, la debida protección frente a los mismos, generando el órgano judicial, a tales efectos, ese denominado Estatuto Integral de Protección que comprende, desde el punto de vista procesal, la posibilidad de adoptar, bajo su manto, medidas cautelares penales y civiles. Por lo que, por consiguiente, la solicitud de una orden de protección implica la posible y probable petición de adopción de medidas cautelares tanto civiles como penales.

Las medidas cautelares de naturaleza penal que se pueden solicitar, en el marco de una petición de una orden de protección, podrán consistir en “..... cualquiera de las previstas en la legislación procesal criminal” (art. 544 ter, 6 LECrim), esto es cualquiera de las reguladas en la LECrim, a las que hay que añadir las que se relacionan en el art. 64 de la LIVG.

Dos de los requisitos comunes a las medidas de protección citadas, previstos tanto en la LECrim como en la LIVG, son, por un lado, que todas estas medidas podrán acordarse acumulada o separadamente (art. 64, 6 LIVG), y, por el otro, que pueden ser decretadas o bien en el marco de una Orden de Protección o bien con independencia de su solicitud.

Por consiguiente, y a la vista de todo lo expuesto, las víctimas de violencia doméstica y de género podrán presentar ante la autoridad competente del Estado español, la solicitud de adopción de una OEP, siempre y cuando, como primer requisito, ya hubiera sido decretada a su favor una o varias medidas de protección bien en el marco de una Orden de Protección o bien con independencia de la misma, siendo ello posible como consecuencia de la directa aplicación de la Directiva.

Pero esta afirmación genérica podría resultar modulada por las propias disposiciones contenidas en la Directiva que restringen con mucho la posibilidad de solicitar una OEP al regular una serie de requisitos relativos a cuestiones tales como los sujetos legitimados para

\footnotetext{
${ }^{6}$ En cuanto a la controvertida cuestión de la naturaleza jurídica de las medidas previstas en la Ley Integral, véase, entre otros, Aragoneses Alonso, S. "Las medidas judiciales de protección y de seguridad de las víctimas de la violencia de género", en AA.VV. "Tutela penal y tutela judicial frente a la violencia de género", Madrid, 2006, pp. 168 y 169; Senés Motilla, C. "Consideraciones sobre las medidas judiciales de protección y de seguridad de las víctimas de la violencia de género", Revista La Ley, 5 de febrero de 2007, n 6644, p. 1; Gómez Colomer, J-L, "Violencia de género y proceso", Valencia, 2007, pp. 215 a 218.
} 
instarla o a las concretas medidas que pueden ser objeto de una OEP, y que, en no pocas ocasiones, suponen una limitación a los específicamente previstos en el Derecho procesal penal español.

\section{SUPUESTOS EN QUE PROCEDE:}

Partiendo de la premisa de que la OEP únicamente podrá ser solicitada con el único objetivo de que la protección derivada de determinadas medidas de protección dictadas con arreglo al Derecho interno de un Estado miembro (en este caso el Estado español) pueda ampliarse a otro Estado miembro en el que la persona objeto de la protección decida residir o permanecer, el requisito previo e ineludible que determina la admisibilidad de su solicitud consiste, como hemos señalado anteriormente, en que, la autoridad competente que la recibe haya acordado previamente una o varias medidas de protección de una víctima de violencia doméstica o de género.

Como ya hemos visto, en el caso español, es posible que tales medidas de protección hayan sido adoptadas o bien en el marco de una Orden de Protección, o bien con independencia de la misma, lo que condicionará, desde nuestro punto de vista, y en aplicación de la Directiva, el contenido de la OEP que eventualmente pueda ser solicitada y, posteriormente, adoptada.

Y, en efecto, si bien como prevé tanto la LECrim como la LIVG, la Orden de Protección puede comprender la adopción de medidas cautelares (y, por tanto, prohibiciones o restricciones) tanto civiles como penales, por el contrario la OEP solo podrá adoptarse en relación con las medidas de protección de naturaleza penal. Es más, no con respecto a la totalidad de las medidas penales, objeto de la Orden de Protección dictada por los órganos competentes del Estado de emisión, sino únicamente respecto a las relacionadas en el art. 5 de la Directiva.

En este sentido, el art. 2 de la Directiva dispone expresamente que por "medida de protección" a los efectos de solicitud de una OEP ha de entenderse "una resolución en materia penal, adoptada en el Estado de emisión con arreglo a su legislación y procedimientos nacionales"; y, a pesar de la poco afortunada redacción de este precepto que nos llevaría a pensar que podría tratarse de una resolución dictada en un proceso penal pudiendo contener la misma medidas de protección tanto penales como civiles (como ocurre con la Orden de Protección española), por el contrario, la interpretación conjunta de los arts.2 y 5 de la Directiva, conduce claramente a la conclusión de que las medidas de protección objeto de una OEP han de ser estrictamente de carácter penal y nunca de naturaleza civil. Es más, dentro de las medidas de protección de naturaleza penal que pueden haberse adoptado en una Orden de Protección dictada en España, las que puedan ser objeto de una posterior OEP quedarían circunscritas a alguna o algunas de los tres tipos de medidas tasadas en el art.5 de la Directiva.

3. PROCEDIMIENTO DE ADOPCIÓN DE LA ORDEN EUROPEA DE PROTECCIÓN:

\section{A. LEGITIMACIÓN}

Por lo que se refiere a los sujetos legitimados para solicitar una OEP, la Directiva exige la concurrencia cumulativa de los siguientes requisitos: 
- En primer lugar, la persona solicitante de la OEP ha de ser una persona física que se encuentra ya protegida por una medida de protección dictada en el Estado de emisión (arts. 1, 2.3) y 5 de la Directiva); de lo que se deduce que la solicitud de adopción de una OEP ante las autoridades competentes del Estado español podrá ser presentada únicamente por aquellas víctimas de violencia doméstica o de género que ya gozan de protección, o bien por estar amparadas por una Orden de Protección, o bien por alguna de las medidas de protección acordadas con independencia de ésta.

- En segundo lugar, la persona solicitante de la OEP, previamente protegida, decide residir o reside ya en otro Estado miembro, o decide permanecer o permanece ya en otro Estado miembro (art.6.1 de la Directiva), y estima que existe un peligro para su vida, su integridad física o psicológica y su dignidad, su libertad individual o su integridad sexual, que justifica que en el Estado miembro al que se ha desplazado o se va a desplazar se mantenga la protección de la que ya goza en el Estado en el que se acordó la medida de protección (arts. 1 y 2.1) de la Directiva).

- En tercer lugar, y como taxativamente señala el art. 6.2 de la Directiva, solo está legitimada para solicitar una OEP la persona protegida, con la única excepción prevista en el art. 6.6 de la Directiva para los supuestos de que aquélla tenga un tutor o un representante, en cuyo caso dicho tutor o representante ostentará legitimación para presentar la solicitud en nombre y representación de la víctima, en clara alusión a los sujetos especialmente vulnerables, como son los casos de menores no emancipados, sujetos incapacitados o incapaces o personas con discapacidad (a los que expresamente se refiere el Considerando 16 de la Directiva).

Se excluye, por consiguiente, la posibilidad de que la OEP pueda ser acordada de oficio por la autoridad competente del Estado de emisión, previéndose, únicamente que dicha autoridad, que hubiera adoptado la previa medida de protección en el ámbito del Derecho interno, informe a la persona protegida de la eventualidad de solicitar que se dicte una OEP y de las condiciones básicas para la presentación de la misma, así como aconsejarla que presente la solicitud antes de salir del territorio del Estado de emisión (art. 6.5 de la Directiva).

En este punto conviene poner de manifiesto la notable diferencia que existe entre la Directiva y la regulación española en lo que al elenco de sujetos legitimados para solicitar una Orden de Protección se refiere, ya que éste último es considerablemente más extenso que el previsto en aquélla para la solicitud de una OEP.

Por lo que se refiere a los sujetos legitimados para solicitar una Orden de Protección en España, es necesario acudir a lo dispuesto, de un lado, en el apartado $2^{\circ}$ del art. 544 ter de la LECrim (legitimación en casos de violencia doméstica), y, de otro, el art. 61,2 LIVG (legitimación en casos de violencia de género).

Conforme a lo dispuesto en el primero de los preceptos citados, la Orden de Protección en los supuestos de violencia doméstica podrá ser acordada por el Juez de oficio o a instancia de la víctima o persona que tenga con ella alguna de las relaciones mencionadas en el art. 173,2 del $\mathrm{CP}, 7$ y, asimismo, podrán instar su adopción las entidades u organismos asistenciales,

\footnotetext{
7 El art. 173,2 del CP alude a los siguientes sujetos:

- Cónyuge o persona que esté o haya estado ligada al agresor por una análoga relación de afectividad aún sin convivencia.

- Descendientes, ascendientes o hermanos por naturaleza, adopción o afinidad, propios o del cónyuge o conviviente. 
públicos o privados, que tuvieran conocimiento de la comisión de un hecho delictivo relacionado con la violencia doméstica.

Por su parte, el art. 61,2 de la LIVG dispone que "en todos los procedimientos relacionados con la violencia de género, el Juez competente, de oficio o a instancia de las víctimas, de los hijos, de las personas que convivan con ellas o se hallen sujetas a su guarda y custodia, del Ministerio Fiscal o de la Administración de la que dependan los servicios de atención a las víctimas o su acogida, deberá pronunciarse, en todo caso, sobre la pertinencia de la adopción de las medidas cautelares y de aseguramiento contempladas en este capítulo ...", entre las que se encuentra la Orden de Protección.

Para la Fiscalía General del Estado existen una notable diferencia en cuanto a la legitimación activa para instar una Orden de Protección, según ésta tenga por objeto amparar una situación de violencia doméstica o, por el contrario, de violencia de género, ya que, como afirma en su Circular 4/2005 relativa a Los criterios de aplicación de la Ley Orgánica de Medidas de protección integral contra la violencia de género "de este modo se prevé una extensa legitimación activa para solicitar las medidas de la LO 1/2004, que si bien, de un lado, es más amplia que la prevista en el art. 544 ter LECrim en relación con las solicitudes de orden de protección -ya que éste, con relación a las entidades y organismos asistenciales, establece su obligación de poner los hechos en conocimiento del juez de guardia o del Ministerio Fiscal, mientras que el art. 61.2 LOMPIVG contempla que, sea la propia Administración, no se refiere por tanto a entidades de carácter privado, quien inste directamente las medidas previstas en el Capítulo IV- de otro, es más restringida dado que mientras el párrafo segundo del art. 544 ter legitima a las personas que tengan con la víctima alguna de las relaciones contempladas en el art. 173.2 CP, el art. 61.2 LOMPIVG en el caso de cónyuges o parejas, ascendientes, hermanos o descendientes que no sean hijos de la víctima, sólo los habilita si conviven con la víctima o están sujetos a su guarda y custodia”.

Sin embargo, a pesar de las restricciones contempladas en la Directiva en orden a la legitimación de determinados sujetos, entendemos que, puesto que, por un lado, la solicitud de una OEP exige como requisito de admisibilidad la preexistencia de una o varias medidas de protección adoptadas ya a favor de la víctima en el Estado de emisión y, por el otro, que la finalidad de la OEP no es otra que dotar a aquellas medidas preacordadas de efectividad transfronteriza, el único sujeto legitimado para la solicitud de la OEP sea la propia víctima o, excepcionalmente, su representante legal o tutor para los casos de menores no emancipados, sujetos incapacitados o incapaces o personas con discapacidad.

\section{B. ÓRGANOS COMPETENTES PARA RECIBIR LA SOLICITUD Y ADOPTAR LA OEP.}

Si como ya hemos señalado a lo largo de este trabajo, la finalidad de la OEP consiste en facultar a una autoridad competente de otro Estado miembro para mantener la protección de la persona en el territorio de ese otro Estado miembro, la efectividad en la adopción y ejecución de una OEP se hace depender de la aplicación del principio de reconocimiento mutuo entre dos Estados de la Unión: el Estado de emisión y el Estado de ejecución.

\footnotetext{
- Menores o incapaces que con él convivan o que se hallen sujetos a la potestad, tutela, curatela, acogimiento o guarda de hecho del cónyuge o conviviente.

- Persona amparada en cualquier otra relación por la que se encuentre integrada en el núcleo de su convivencia familiar.

- Personas que, por su especial vulnerabilidad, se encuentren sometidas a custodia o guarda en centros públicos o privados.
} 
La Directiva define el Estado de emisión como "el Estado miembro en el que se haya adoptado una medida de protección que constituya la base para la emisión de una orden europea de protección" (art. 2.5)), y el Estado de ejecución como "el Estado miembro al que se haya transmitido una orden europea de protección con vistas a su reconocimiento" (art. 2.6)).

Asimismo establece la Directiva que cada Estado miembro deberá comunicar a la Comisión la autoridad o autoridades judiciales, o autoridades equivalentes, que son competentes, con arreglo a su Derecho nacional, para dictar una orden europea de protección y para reconocerla (...), cuando dicho Estado miembro sea, o bien, el Estado de emisión, o bien, el Estado de ejecución (art.4.1).

¿Cuál o cuáles serían, por consiguiente, los órganos competentes en el ámbito del Derecho procesal penal español, para emitir una OEP, concretamente en relación con los supuestos de violencia doméstica o de género? La cuestión planteada no resulta baladí si se tiene en consideración que, en nuestro ordenamiento procesal penal, para los supuestos de violencia doméstica y de género, cuestión distinta será cuáles sean los órganos competentes para recibir una solicitud de medidas de protección o de una Orden de Protección y cuáles son competentes para adoptarlas.

En cuanto a los órganos competentes para recibir la solicitud de adopción de una Orden de Protección o de una medida de protección, conforme a lo dispuesto en el apartado $3^{\circ}$ del art. 544 ter LECrim, podrán ser cualquiera de los siguientes:

- La Autoridad Judicial, entendiendo por tal, tanto el Juez de Violencia sobre la Mujer o un Juzgado de Instrucción en servicio de guardia (para los casos de violencia de género), como el Juzgado de Instrucción (para los casos de violencia doméstica).

\section{- El Ministerio Fiscal.}

- Las Fuerzas y Cuerpos de Seguridad del Estado, que deberán levantar el correspondiente atestado en el que harán constar todas las circunstancias del hecho y los datos de identificación de la víctima y del agresor.

- Las Oficinas de atención a la víctima.

- Los servicios sociales o instituciones asistenciales dependientes de las Administraciones Públicas.

Y, por último, a tenor de lo señalado en el Protocolo para la implantación de la Orden de Protección elaborado por la Comisión de Seguimiento, incluso los Servicios de Orientación Jurídica de los Colegios de Abogados.

En todos estos supuestos el precepto citado establece la obligación de que la solicitud sea remitida de forma inmediata al juez competente.

Recibida la solicitud de la Orden de Protección en el órgano judicial competente (Juez de guardia (art. 87, 1, f) LOPJ) o Juez de Violencia sobre la Mujer (art. 87 ter)), éste deberá comprobar para los casos de violencia de género, en primer lugar, si se trata de un acto de violencia de género y si el hecho es constitutivo de delito o de falta.

Hecha esta comprobación, el trámite subsiguiente, varía en función de si la solicitud fue recibida por un Juzgado de Instrucción en servicio de Guardia o, por el contrario, por un Juzgado de Violencia sobre la Mujer. 
Si la solicitud fue recibida por un Juzgado de Guardia, y el hecho denunciado en la misma es constitutivo de la falta tipificada en el art. 620 del CP (amenaza con armas u otros instrumentos peligrosos; amenaza, coacción, injuria o vejación injusta de carácter leve), conforme a lo dispuesto en los art. 962,1 y 544 ter, 4 de la LECrim, incoará un Juicio de faltas, convocando a una audiencia urgente a la víctima o su representante legal, al solicitante (en el caso de que no fuera la propia víctima), al agresor y al Ministerio Fiscal, que tiene por objeto determinar si procede o no adoptar la Orden de Protección.

Es posible, sin embargo, que el Juez de Guardia acuerde directamente, al amparo de lo dispuesto en el art. 923 de la LECrim la celebración inmediata del Juicio de faltas, en el marco del cual es perfectamente factible dilucidar la procedencia o no de acordar la Orden de Protección, además de dictarse la oportuna sentencia (art. 544 ter, 4 LECrim).

Si la solicitud fue recibida por un Juzgado de Guardia, y el hecho denunciado en la misma es constitutivo de delito, puede ocurrir:

a) Que se trate de alguno de los delitos que, conforme a lo dispuesto en los arts. 795 y siguientes de la LECrim, hayan de enjuiciarse por los trámites del Procedimiento para el Enjuiciamiento rápido de determinados delitos, en cuyo caso, el Juez de guardia, a tenor de lo dispuesto en el art. 797 bis LECrim, y solo para los casos de violencia de género, no convocará a la audiencia a la que hace referencia el art. 544 ter, 4 LECrim, sino que habrá de remitir las actuaciones practicadas al Juzgado de Violencia sobre la Mujer a la mayor brevedad posible y poner a su disposición al detenido.

No ocurre lo mismo en los supuestos de violencia doméstica en los que, conforme a lo establecido en el art. 544 ter, 4 LECrim, sí parece posible que el Juez de Guardia convoque la audiencia para determinar si procede o no acordar una Orden de Protección.

b) Que se trate de cualquier otro tipo delictivo que haya de sustanciarse por los trámites del Procedimiento Abreviado o del Proceso Ordinario por delitos graves (Sumario Ordinario), en cuyo caso, tratándose de un acto de violencia de género, y en aplicación de lo dispuesto en los arts. 87 y 87 ter de la LOPJ, parece el legislador derivar la competencia para la celebración de la audiencia preferentemente al Juzgado de Violencia sobre la Mujer, por lo que, el Juez de Guardia, deberá remitirle las actuaciones lo antes posible. Ello se deduce claramente de lo dispuesto en el art. 87, 1, f) LOPJ que establece que los Juzgados de Instrucción (en este caso en servicio de guardia) conocerán en el orden penal "de la adopción de la orden de protección a las víctimas de violencia sobre la mujer cuando esté desarrollando funciones de guardia, siempre que no pueda ser adoptada por el Juzgado de Violencia sobre la Mujer". ${ }^{.}$

\footnotetext{
8 Al respecto, el Acuerdo de 17 de julio de 2008, del Pleno del Consejo General del Poder Judicial, por el que se modifica el Reglamento 1/2005, de 15 de septiembre, de los aspectos accesorios de las actuaciones judiciales, en materia de servicio de guardia en los Juzgados de Violencia sobre la Mujer, da una nueva redacción al apartado $4^{\circ}$ del art. 42 del mencionado Reglamento estableciendo que : "salvo en aquellas demarcaciones donde exista servicio de guardia de los Juzgados de Violencia sobre la Mujer, también será objeto de servicio de guardia de los Juzgados de Instrucción o de Primera Instancia la regularización de la situación personal de quienes sean detenidos por su presunta participación en delitos cuya instrucción sea competencia de los Juzgados de Violencia sobre la Mujer y la resolución las solicitudes de adopción de las órdenes de protección de las víctimas de los mismos, siempre que dichas solicitudes se presenten y los detenidos sean puestos a disposición judicial fuera de las horas de audiencia de dichos Juzgados. A estos efectos, el Juez de Instrucción que atienda el servicio de guardia actuará en sustitución del correspondiente Juez de Violencia sobre la Mujer. Adoptada la decisión que proceda, el Juez de Instrucción
} 
Al igual que en el supuesto anterior, no sucedería lo mismo en los casos de violencia doméstica en los que, conforme a lo establecido en el art. 544 ter, 4 LECrim, sí parece posible que el Juez de Guardia conserve la competencia para convocar la audiencia y determinar si procede o no acordar una Orden de Protección.

Si la solicitud es recibida por el Juzgado de Violencia sobre la Mujer (para actos de violencia de género) o por un Juzgado de Instrucción (para actos de violencia doméstica o de violencia de género), con independencia de los trámites a seguir, son ambos competentes para la celebración de la audiencia.

Pues bien, si como se ha puesto de manifiesto, la solicitud de una Orden de Protección o de una medida de protección es susceptible de ser presentada no solo ante los órganos judiciales competentes para adoptarla, sino también ante otros órganos de naturaleza no jurisdiccional, no ocurre lo mismo respecto de la solicitud de adopción de una OEP.

Y ello es así, en tanto en cuanto, en relación con la OEP, los órganos competentes tanto para recibir la solicitud como para adoptarla vienen a ser coincidentes: o los Juzgados de Instrucción o los Juzgados de Violencia sobre la Mujer (según se trate de supuestos de violencia doméstica o de género, respectivamente),

En efecto, dado que la propia Directiva, al definir el Estado de emisión se refiere a él como "el Estado miembro en el que se haya adoptado una medida de protección que constituya la base para la emisión de una orden europea de protección" (art. 2.5)); siendo que la adopción de las medidas de protección preexistentes es competencia exclusiva de los órganos judiciales, y no tomando la Directiva en consideración las autoridades ante las que puede haberse presentado la solicitud de adopción de la medida, base de la OEP, podemos concluir, a nuestro juicio, que, en nuestro Derecho procesal penal la competencia para adoptar la OEP viene diferida exclusivamente a los órganos judiciales competentes antes mencionados para los supuestos de violencia doméstica y de género.

Por último es necesario señalar que la Directiva sí contempla, sin embargo, la posibilidad de que la solicitud de la OEP pueda ser presentada o bien ante la autoridad competente del Estado de emisión, o bien ante la autoridad competente del Estado de ejecución, aunque, en este último caso, la autoridad competente del Estado de ejecución carece de competencia para decidir sobre la admisión o no de la solicitud debiendo transmitirla a la autoridad competente del Estado de emisión que ostenta, en exclusiva la competencia para decidir sobre su admisibilidad o no y, por tanto, para la adopción de una OEP (arts. 1, 2.5), 6.3 y 13 de la Directiva).

Es más, la autoridad competente del Estado de emisión no solo posee competencia exclusiva en materia de admisibilidad y adopción de la OEP, sino también en lo que respecta a la prórroga, revisión, modificación, revocación o anulación de la medida de protección en cuya existencia se sustenta la OEP (art. 13.1 a) de la Directiva).

C. TRAMITACIÓN DE LA SOLICITUD Y ADOPCIÓN DE LA OEP ANTE LOS ÓRGANOS JUDICIALES ESPAÑOLES

Determinados ya, a nuestro juicio, y para los casos de violencia doméstica y de género, tanto los sujetos legitimados para solicitar una OEP como los órganos judiciales competentes para

en funciones de guardia remitirá lo actuado al órgano competente y pondrá a su disposición, en su caso, al imputado". 
su recepción y adopción, procede examinar cuáles sean los trámites que han de seguirse y cuáles los requisitos de la solicitud y adopción de la misma.

- En primer lugar, es necesario recalcar que la solicitud de la OEP exige, como requisito de admisibilidad, que previamente haya sido ya adoptada alguna o algunas de las medidas de protección previstas en el art. 5 de la Directiva, por el órgano competente del Estado de emisión.

- En segundo lugar, es preciso que la persona solicitante de la OEP ponga de manifiesto en su solicitud su decisión de trasladarse a otro Estado Miembro (bien para residir en él, bien para permanecer en el mismo por un tiempo limitado), concretando la duración del periodo o periodos en que tiene intención de permanecer en el Estado de ejecución.

- En tercer lugar, es necesario alegar en la solicitud que la OEP se presenta ante el temor fundado de que el agresor pueda llevar a cabo, en el Estado de ejecución, actos delictivos que pongan en peligro su vida, su integridad física o psicológica y su dignidad, su libertad individual o su integridad sexual, razón por la que se pide el mantenimiento en el territorio del Estado de ejecución de la protección de la que ya goza la víctima en el Estado de emisión.

- La solicitud únicamente podrá ser presentada para instar la protección de una sola persona (la víctima de violencia doméstica o de género), sin que sea posible solicitar la extensión de esa protección de la OEP "para proteger a un familiar de la principal persona protegida” (Considerando 12 y art. 6.2 de la Directiva), aunque ello no es obstáculo para que este familiar también puede solicitar y quedar amparado por una orden europea de protección, en las condiciones establecidas en la Directiva.

No es extraña a nuestro ordenamiento procesal penal, esta naturaleza individual de la solicitud y del alcance de la adopción de la OEP, ya que, en lo que respecta a la Orden de Protección española ésta posee, asimismo, carácter individual, de tal manera que no será posible ampliar la misma amparando a otro sujeto distinto del que inicialmente la solicitó y que, durante la tramitación de las actuaciones, pueda estar sufriendo agresiones por parte del maltratador. Es por ello que el art. 544 ter, 11 LECrim, establece que, en tales casos, el Juez podrá acordar una Orden de Protección para proteger individualizadamente a este último.

- Presentada la solicitud de la OEP (para los supuestos de violencia doméstica o de género) ante el órgano judicial competente (en el caso de España, cuando actúa como Estado de emisión) o recibida la misma (en los supuestos en que la víctima la hubiera solicitado ante las autoridades competentes del Estado de ejecución), nada especifica la Directiva en cuanto al procedimiento a seguir para su tramitación (con excepción de alguna referencia a los derechos de audiencia e impugnación), por lo que, desde nuestro punto de vista, habría que acudir a las normas de Derecho interno en todo lo que resultaran aplicables.

En este sentido, es importante partir de la premisa de lo dispuesto en el art. 6.4 de la Directiva, conforme al cuál "antes de emitir la orden europea de protección, se dará a la persona causante del peligro el derecho a ser oída y a impugnar la medida de protección, en caso de que no hubiera tenido esos derechos en el curso del procedimiento que haya conducido a la adopción de la medida de protección".

En el mencionado precepto se exige a las autoridades competentes de los Estados miembros (cuando actúan como Estado de emisión de una OEP) el escrupuloso respeto de los derechos de audiencia y recurso que han de ser garantizados al sujeto causante del peligro puesto de manifiesto por la persona solicitante de la OEP, pero únicamente cuando en el previo procedimiento de adopción de la medida o medidas de protección acordadas, base inexcusable de la OEP, no hubieran sido observados. 
En el caso español, para la adopción de una OEP no será necesario ni oír al sujeto causante del peligro, ni reconocerle el derecho a impugnar la resolución en que se adopte una OEP, dado que, tanto para la adopción de medidas de protección como para la adopción de una Orden de Protección (base de la solicitud de la OEP), la LECrim prevé la celebración de una audiencia o vista (arts. 544 bis y 544 ter, 4) en la que serán oídos tanto el agresor como la víctima, y tras la misma, la decisión del órgano judicial sobre su adopción que revestirá la forma de auto, contra el que cabe interponer por parte del agresor, recurso de reforma, $y$, en su caso, posterior recurso de apelación, en aplicación de las normas generales sobre recursos previstas en la LECrim.

- En cuanto a la forma que ha de revestir la resolución en que se adopte una OEP, dado que la Directiva nada señala a estos efectos, entendemos que, por aplicación analógica de los preceptos de la LECrim que regulan la forma que ha de adoptar la resolución en que se acuerden medidas de protección o una Orden de Protección, ésta ha de ser necesariamente un auto.

- En cuanto al contenido del auto en que se adopta una OEP (para los supuestos de violencia doméstica o de género), que necesariamente ha de ser motivado, el órgano judicial competente ha de tomar en consideración una serie de circunstancias derivadas de la aplicación conjunta de los preceptos de la Directiva y de lo dispuesto tanto en la LECrim como en la LIVG. Estas circunstancias son las siguientes:

- La duración del período o períodos en que la persona protegida tiene intención de permanecer en el Estado de ejecución (art. 6.1 de la Directiva)

- La importancia de la necesidad de protección, en el sentido de que el órganos judiciales competentes habrán de valorar y motivar la necesidad de mantener la protección de la persona en el territorio de otro Estado miembro, derivada de indicios fundados de que el agresor pueda cometer, en el Estado de ejecución, actos delictivos que puedan poner en peligro la vida, la integridad física o psicológica y la dignidad, la libertad individual o la integridad sexual de la víctima (art. 6.1 de la Directiva, art 544 ter LECrim y art. 68 de la LIVG).

- En caso contrario, de no concurrir estas circunstancias, el órgano judicial denegará la solicitud de emisión de la OEP e informará a la persona protegida de todas las posibles vías de recurso que sean de aplicación en el Derecho nacional para oponerse a dicha decisión (art. 6.7 de la Directiva).

- Por último, y aun cuando nada especifique la Directiva, entendemos, desde nuestro punto de vista, que, una vez dictado el auto acordando la OEP, ésta deberá ser “... notificada a las partes, y comunicada por el juez inmediatamente, mediante testimonio íntegro, a la víctima..." (art. 544 ter, 8 LECrim). Además, entendemos que procedería acordará su inmediata inscripción en el Registro Central para la Protección de las Víctimas de la Violencia Doméstica (art. 544 ter, 10 LECrim), cuyo funcionamiento aparece previsto en el Real Decreto 355/2004, de 5 de marzo (modificado por el Real Decreto 513/2005, de 9 mayo), y que, como señala el art. $2^{\circ}$ "... constituye un sistema de información relativo a penas y medidas de seguridad impuestas en sentencias por delito o falta y medidas cautelares y órdenes de protección acordadas en procedimientos penales en tramitación, contra alguna de las personas mencionadas en el artículo 173.2 del Código Penal". 


\section{EL CONTENIDO DE LA ORDEN EUROPEA DE PROTECCIÓN}

El art 5 de la Directiva establece que "solo se podrá dictar una orden europea de protección cuando previamente se haya adoptado en el Estado de emisión una medida de protección que imponga a la persona causante del peligro una o varias de las siguientes prohibiciones o restricciones:

a) prohibición de entrar en determinadas localidades, lugares o zonas definidas en las que la persona protegida reside o que frecuenta;

b) prohibición o reglamentación de cualquier tipo de contacto con la persona protegida, incluidos los contactos telefónicos, por correo electrónico o postal, por fax o por cualquier otro medio, o

c) prohibición o reglamentación del acercamiento a la persona protegida a una distancia menor de la indicada en la medida.

La Directiva contiene, por consiguiente, una lista exhaustiva de prohibiciones y restricciones, es decir, de medidas de protección, que, una vez impuestas en el Estado de emisión e incluidas en la OEP, deben reconocerse y ejecutarse en el Estado de ejecución (Considerando 19 de la Directiva). De tal manera que, a la vista del tenor literal del art. 5 de la Directiva, únicamente podría adoptarse una OEP si previamente se hubiera acordado alguna o algunas de las concretas medidas previstas en este precepto y no otras.

Reconoce la propia Directiva que "a escala nacional pueden existir también otras medidas de protección, como la obligación de que la persona causante del peligro permanezca en un lugar determinado, si la legislación nacional así lo prevé. Tales medidas pueden imponerse en el Estado de emisión en el marco del procedimiento de adopción de una de las medidas de protección que, de acuerdo con la presente Directiva, puede ser la base de una orden europea de protección" (Considerando 19 de la Directiva).

Dado que la adopción de una OEP tiene, necesariamente, su fundamento en la preexistencia de una medida de protección ya acordada por las autoridades competentes del Estado de emisión, procede examinar si las medidas de protección, que para el ámbito de la violencia doméstica y de género, prevén tanto la LECrim como la LIVG, pueden constituir, al ser adoptadas por los órganos judiciales españoles, la base para la adopción de una OEP.

En este sentido, las medidas de protección de naturaleza penal y cautelar que se pueden adoptar, en el marco de una petición de una orden de protección o con independencia de la misma, podrán consistir, como ya hemos señalado anteriormente, en “..... cualquiera de las previstas en la legislación procesal criminal” (art. 544 ter, 6 LECrim), esto es cualquiera de las reguladas tanto en la LECrim en la LIVG (específicamente para los casos de violencia de género).

Estas medidas de protección de naturaleza penal y cautelar pueden ser de dos tipos: de un lado, las que podríamos denominar medidas cautelares "comunes", esto es, la citación cautelar (arts. 486 y ss LECrim), la detención (arts. 489 y ss LECrim), la libertad provisional (arts. 528 y ss y 505 LECrim) y la prisión provisional (arts. 502 y ss LECrim), y, de otro, las medidas cautelares específicas para los casos de violencia doméstica y de género, previstas 
en los arts. 544 bis de la LECRim y 64 de la LIVG que pueden consistir en alguna o algunas de las siguientes:

a) La salida obligatoria del agresor del domicilio en el que hubiera estado conviviendo o tenga su residencia la unidad familiar (art. 64, 1 LIVG).

b) La medida de alejamiento (art. 64, 3 y 4 LIVG).

c) La prohibición al agresor de comunicarse con la persona o personas que se le indique (art. 64, 5 LIVG).

d) La prohibición de residir en un determinado lugar, barrio, municipio, provincia, u otra entidad local o Comunidad Autónoma (art. 544 bis, inciso $1^{\circ}$ LECrim).

e) La prohibición de acudir a determinados lugares, barrios, municipios y provincias $\mathrm{u}$ otras entidades locales o Comunidades Autónomas (art. 544 bis, inciso $2^{\circ}$ LECrim).

Por consiguiente, y en aplicación del art. 5 de la Directiva, en relación con los arts. 544 bis de la LECRim y 64 de la LIVG, entendemos, que, habiéndose adoptado cualquiera de las medidas de protección relacionadas en estos últimos preceptos, la víctima dispondrá de base suficiente para presentar, ante el mismo órganos judicial, la solicitud de adopción de una OEP. Por último, y en cuanto a la forma y contenido concreto de la OEP, el art. 7 de la Directiva dispone lo siguiente:

"La orden europea de protección se emitirá con arreglo al modelo que figura en el anexo I de la presente Directiva. Deberá contener, en particular, la siguiente información:

a) identidad y nacionalidad de la persona protegida, y las de su tutor o representante en caso de que la persona protegida sea menor o legalmente incapaz;

b) fecha a partir de la cual la persona protegida se propone residir o permanecer en el Estado de ejecución, así como el período o los períodos de permanencia, si se conocen;

c) nombre, dirección, números de teléfono y fax, y dirección de correo electrónico de la autoridad competente del Estado de emisión;

d) referencia (por ejemplo, por medio de un número y de una fecha) del acto jurídico que contiene la medida de protección en la que se funda la orden europea de protección;

e) resumen de los hechos y circunstancias que dieron lugar a la imposición de la medida de protección en el Estado de emisión;

f) prohibiciones o restricciones impuestas a la persona causante del peligro en virtud de la medida de protección en la que se funda la orden europea de protección, duración de las mismas, indicación de la pena o sanción aplicable, si ha lugar, en caso de incumplimiento de la correspondiente prohibición u obligación; 
g) en su caso, utilización de un dispositivo técnico que se haya suministrado a la persona protegida o a la persona causante del peligro como medio para hacer cumplir la medida de protección;

h) identidad, nacionalidad y datos de contacto de la persona causante del peligro; i) cuando la autoridad competente del Estado de emisión disponga de esta información sin necesidad de proceder a nuevas investigaciones, indicación de si se ha concedido a la persona protegida o a la persona causante del peligro asistencia jurídica gratuita en el Estado de emisión;

j) si ha lugar, la descripción de otras circunstancias que podrían influir en la valoración del peligro al que está expuesta la persona protegida;

k) indicación expresa, en su caso, de que ya se ha transmitido al Estado de supervisión - si este es distinto del Estado de ejecución de la orden europea de protección - una sentencia, según la definición del artículo 2 de la Decisión marco 2008/947/JAI, o una resolución sobre medidas de vigilancia, según la definición del artículo 4 de la Decisión marco 2009/829/JAI, e indicación de la autoridad competente de ese Estado para la ejecución de dicha sentencia o resolución". 
